\title{
The use of the titrating delayed matching-to-sample procedure for analyzing drug effects
}

\author{
L. J. WOODWARD, J. E. WATSON, N. M. BLAMPIED, and N. N. SINGH \\ University of Canterbury, Christchurch, New Zealand
}

(K. T. Strongman, Sponsor)

\begin{abstract}
A titrating delayed matching-to-sample (TDMTS) procedure, in which the delay between the sample and comparison stimuli depends on the subject's performance, was used to assess the effects of $0.5 \mathrm{mg} / \mathrm{kg}$ of haloperidol in pigeons. The results showed that the decrease in the limit of delay sustained by the subjects in the drug condition could not be attributed to drug effects on short-term memory, because the limit of delay measure was confounded by the effect of the drug on psychomotor responding. Implications of the use of the TDMTS procedure are discussed.
\end{abstract}

Matching-to-sample (MTS) is an experimental procedure that has been used to assess the effects of drugs on stimulus control. In MTS, a trial begins with the presentation of a sample stimulus. After an appropriate response is made, two or more comparison stimuli are presented, one of which is identical to the sample stimulus. To obtain a reinforcer, the subject must respond to the comparison stimulus that "matches the sample" (McMillan, 1981).

When a delay is interpolated between the sample and comparison stimuli (delayed matching-to-sample, DMTS), the procedure becomes useful for the study of both concept formation and short-term memory (STM) in animals (McMillan, 1981). The DMTS paradigm has two advantages in the study of STM. First, it minimizes the influence of peripheral mediating responses, and second, DMTS tasks may employ exteroceptive stimuli that permit a rigorous manipulation of stimulus parameters and precise specification of stimulus and retention interval duration (Pontecorvo, 1983).

Performance under DMTS, across a variety of species, shows that with increases in the delay interval, there is a corresponding decrease in the accuracy of the animals' performance. Thompson (1978) has suggested that DMTS might be more sensitive to drug effects than is MTS because DMTS is presumably under weaker control by the sample stimulus. Stimulus control by the sample stimulus should weaken progressively as the delay increases. Therefore, under DMTS, drug effects might be seen at

\footnotetext{
This report is based on data from a project submitted by the first author in partial fulfillment of the requirements for a master's degree in psychology. The authors acknowledge the assistance of the following people: Chris van Halewyn for writing the computer program, Ijan Beveridge for his care of the animals, and Robin Phillips for his assistance in the preparation of this manuscript. Requests for reprints should be addressed to L. Woodward, Department of Psychology, University of Canterbury, Christchurch, New Zealand.
}

doses lower than those at which effects appear under MTS, or larger drug effects may be seen at the same dose as the delay increases (McMillan, 1981). The DMTS procedure has proved useful in the assessment of the effects of a variety of drugs (Heise \& Milar, 1984; Thompson, 1978).

In the standard DMTS procedure, the delay values at which the subjects work are usually arbitrarily set by the experimenter. One variation of the DMTS procedure is the titrating DMTS procedure (TDMTS), in which the delay between the sample and comparison stimuli varies depending on the subject's performance. On the first trial, the delay is zero, and accurate performance results in an increase in the delay value on subsequent trials. Inaccurate performance results in a decrease in the value of the delay. When the subject performs well, the delay interval progressively increases until it reaches a stable level at which the interval increases as frequently as it decreases (Cumming \& Berryman, 1965).

Although the procedure appears to have a number of advantages for investigations of pharamacological agents, including its ability to provide an immediate and continuous record of the subject's ability to maintain a delay, it has not been used extensively to date. Scheckel (1963, cited in Thompson, 1978) used a modified TDMS procedure to examine the effects of chlorpromazine and chlordiazepoxide on the performance of rhesus monkeys. Following two correct responses by a monkey, the delay for the next trial increased one step in a predetermined sequence $(1,3,7.5,15,30,50,70,90$, and $105 \mathrm{sec})$. If an error was made or if the monkey did not respond to the sample within $10 \mathrm{sec}$ (response failure), the delay for the next trial decreased one step. Scheckel found that chlorpromazine (dose range $0.01-10.0 \mathrm{mg} / \mathrm{kg}$ ) produced a dose-dependent decrease in the limit of delay. Similar doses of chlordiazepoxide resulted in an increase in the limit of delay as the dose increased to $0.3 \mathrm{mg} / \mathrm{kg}$, and then the limit decreased at the larger doses. For both drugs, 
the higher doses produced an increase in response failures. A similar pattern of results was found in a later study by Scheckel, Boff, Dahlen, and Smart (1968), who administered $\Delta^{9}$-THC (dose range of $0.25-4.0 \mathrm{mg} / \mathrm{kg}$ ) to monkeys. As the dose increased, there was a decrease in the limit of delay and an increase in the number of response failures.

These results indicate that all three drugs impaired the subject's memory, since there was a decrease in the limit of delay. However, the drugs also had an effect on the monkey's psychomotor activity as measured by response failures. Since response failures directly contributed to the decrease in the limit of delay, little can be inferred from changes in the delay limit. Both accuracy of performance and psychomotor speed contributed to changes in the delay value.

The aim of this study was to assess the effects of a neuroleptic, haloperidol, on the standard TDMTS procedure in which only incorrect performance led to a decrease in the limit of delay. Previous research using delayed response procedures in monkeys and pigeons has found that haloperidol does not affect stimulus control or STM but that it does cause a decrease in response rate and the number of trials completed (Bartus, 1978; Poling, Picker, $\&$ Thomas, 1984). We hypothesized that the limit of delay would not change significantly in the drug condition, but that measures of response rate would probably decrease.

\section{METHOD}

\section{Subjects}

Subjects were 4 experimentally naive homing pigeons obtained from local suppliers. They were maintained at $80 \%$ of their free-feeding body weights and were individually housed, with unlimited access to water and grit, in a room with constant temperature $\left(24^{\circ} \mathrm{C}\right)$ and illumination (6:00 a.m. to 6:30 p.m.).

\section{Apparatus}

A standard pigeon station (Gerbrands model E3125AA) measuring $50 \mathrm{~cm}$ deep, $50 \mathrm{~cm}$ high, and $20 \mathrm{~cm}$ wide was used. Three response keys, $2.5 \mathrm{~cm}$ in diameter, were located $23 \mathrm{~cm}$ from the bottom of the intelligence panel (front wall) and $8 \mathrm{~cm}$ apart. Each key could be illuminated with white, red, or green light. A minimum of $20 \mathrm{~g}$ of pressure was required for key operation. A centrally located aperture $6 \mathrm{~cm}$ from the floor gave access to a hopper filled with grain. The chamber was illuminated by a $24-V$ houselight and ventilated by a fan. A PDP $11 / 10$ computer controlled experimental events and collected the data.

\section{Behavioral Procedure}

The subjects were initially trained to eat grain from the raised and lighted food hopper and then were autoshaped (Brown \& Jenkins, 1968) to peck the center key when it was illuminated with white light to obtain $3 \mathrm{sec}$ food-hopper access. Keypecks were initially on a continuous reinforcement schedule, followed by a fixed-ratio 5 -sec and fixed-interval 25-sec schedule.

The subjects were then trained to respond to either a red or green sample stimulus and then to the same color presented on one of the side keys. Finally, MTS training began. Each trial began with the illumination of the center key with either red or green light. Five keypecks extinguished this sample stimulus, and comparison stimuli immediately appeared on the side keys, one red and one green. A correct matching response was reinforced with grain, and an incorrect match resulted in a 3-sec blackout. Following the reinforcement or the blackout, there was an intertrial interval of $25 \mathrm{sec}$ before the next trial. The subjects received 72 trials per session. The color of the sample stimulus and the position of the matching comparison stimulus (left or right) was randomized across trials. When the subjects performed consistently at 90-95\% accuracy on the MTS task, the TDMTS procedure was introduced.

At the beginning of each session, the delay between the sample and comparison stimuli was $0 \mathrm{sec}$. Two successive correct matches incremented the delay interval on the next trial by $.5 \mathrm{sec}$, and an incorrect match resulted in a decrement of the delay interval by $.5 \mathrm{sec}$. The limit of delay was defined as the longest delay at which a subject achieved two successive correct matches. The TDMTS training was continued until each subject met a stability criterion, such that the limit of delay varied by no more than $3 \mathrm{sec}$ for 6 consecutive days.

\section{Pharmacological Procedure}

The experimental design for each subject included three 3-week phases: baseline, vehicle control, and drug. Vehicle control and drug injections were given on Mondays and Thursdays. Isotonic saline $(0.9 \% \mathrm{NaCl})$ in a volume of $1 \mathrm{mg} / \mathrm{kg}$ was injected intraperitoneally (IP) as the vehicle control. Haloperidol was injected IP at a dose of $0.5 \mathrm{mg} / \mathrm{kg}$, as a commercially prepared solution diluted with isotonic saline in a volume of $1 \mathrm{mg} / \mathrm{kg}$.

\section{Data Analysis}

Six dependent measures were obtained from each subject on all sessions: (1) the limit of delay; (2) the percentage of correct trials (a widely used measure of response accuracy); (3) the number of trials completed; (4) the percentage of left key responses (a measure of position bias); (5) the mean log of the sample key latency (a measure of the speed at which the subject completed five pecks on the sample key); and (6) the mean log of the comparison key latency (a measure of the time between illumination of the comparison keys and a bird's response).

\section{RESULTS}

\section{Total Number of Trials Completed}

The mean number of trials completed by each subject under each experimental condition is shown in Figure 1. Performance under baseline was high, with all subjects completing the 72 trials on most sessions. Performance remained high in the vehicle control condition. There was
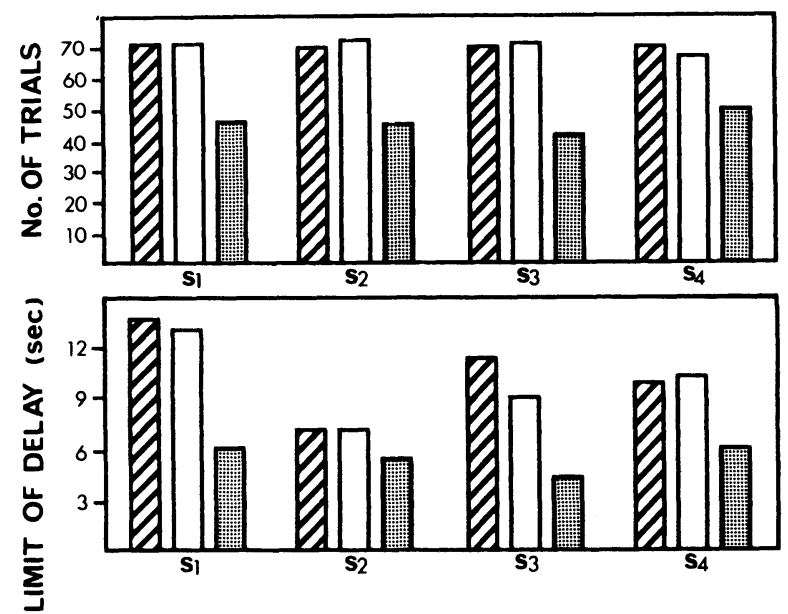

Figure 1. The mean number of trials completed (top) and the mean limit of delay (bottom) for each subject across experimental conditions. From left to right for each subject: baseline, vehicle control, and drug conditions. 
a significant decrease in the number of trials completed during the drug condition when compared with the vehicle control condition $[t(3)=12.4, p<.05]$. (Baseline data were excluded from all analyses, because it was apparent from a visual analysis that the mean performance under baseline and saline conditions was similar.)

\section{Limit of Delay}

The mean limit of delay obtained by each subject under each experimental condition is shown in Figure 1. Subjects 1, 2, and 4 showed similar baseline and vehicle control performances. However, the limit of delay for Subject 3 decreased in the vehicle control condition compared with the limit at baseline. For all subjects, the drug condition resulted in a significant decrease in the mean limit of delay $[t(3)=3.4, p<.05]$.

\section{Other Measures}

The percentage of correct responses, the position bias, and the latency measures were not significantly affected by the drug, although there was a consistent increase in both the sample and comparison latencies in the drug condition. The average sample latency increased from 1.77 in the vehicle control condition to 2.04 in the drug condition, and the average comparison latency increased from 1.09 to 1.23 .

\section{DISCUSSION}

The primary dependent variable of interest was the limit of delay. At the single dose tested $(0.5 \mathrm{mg} / \mathrm{kg})$, haloperidol caused a significant decrease in the limit of delay, suggesting that the drug had an effect on the subject's ability to sustain performance at long delays. This result is not in agreement with past studies, and an evaluation of this drug's effect on other variables provides another explanation for why the limit of delay decreased. If the drug had an effect on stimulus control, there should have been a significant decrease in the percentage of correct responses in the drug condition. Although this did not occur, there was a significant decrease in the number of trials completed in the drug condition; it is likely that this is the reason the limit of delay decreased.

Even with the modified procedure, the limit of delay variable is still confounded by any effects the drug has on psychomotor responding. For example, 2 subjects can obtain the same limit of delay on an experimental session with different behavioral patterns. Subject $X$ may work at $100 \%$ accuracy, but not complete the 72 trials. Subject $Y$ may complete all trials, but at less than $100 \%$ accuracy, and obtain the same limit of delay as Subject X. Unless a subject completes all trials in a session, that subject may not reach an asymptotic delay value. Therefore, the limit of delay depends not only on the accuracy but also on the psychomotor functioning of the subject.

Haloperidol significantly impaired the subjects' ability to complete all 72 trials within each session, clearly confounding any measure of stimulus control by the limit of delay variable. The percentage of correct trials did not change, which is in agreement with past studies using haloperidol (Bartus, 1978; Poling et al., 1984). The effect of haloperidol on psychomotor responding was to retard response initiation rather than the speed of response once it was initiated. This accounts for the lack of significant effects on response latency. No significant difference in the percentage of left key responses indicated that there was no response perseveration during the drug condition.

The results of this study suggest the TDMTS procedure may have limited application in the assessment of drug effects. It may be possible for procedural alterations to overcome some of the present problems. The delay increment could be changed to enable the subjects to reach their optimum delay more rapidly, that is, by having a number of large delay increments at the beginning of each session. Another alternative would be to start the subject on Session $n$ at the delay value they obtained at the end of Session $n-1$, rather than starting all subjects at a delay value of 0 on each session.

The procedure may prove useful in the assessment of the effects of stimulant drugs provided the drugs are administered in ascending doses to minimize the likelihood of psychomotor impairment. It would not be advisable to use the procedure when assessing depressant drugs, unless the subjects had received procedural training while on the drug and the study involved assessing the effects of decreasing the dose of the drug. Such a procedure has been used successfully in the assessment of drug effects in mentally retarded children by Wysocki, Fuqua, Davis, and Breuning (1981), who gradually decreased the dose of thioridazine received by their subjects, and found no impairment of psychomotor responding.

A procedure which may be more useful in the assessment of drugs is DMTS. The delays between the sample and comparison stimuli allow for the assessment of drug effects over various levels of stimulus control. In addition, DMTS procedures have recently been subject to signal detection analysis, which allows the drug effects on discriminability and response bias to be separated and quantified (McCarthy \& White, in press; White, 1985).

\section{REFERENCES}

BARTUS, R. T. (1978). Short-term memory in the rhesus monkey: Effects of dopamine blockade via acute haloperidol administration. Pharmacology, Biochemistry, \& Behavior, 9, 353-357.

Brown, P. L., \& Jenkins, H. M. (1968). Auto-shaping the pigeon's key-peck. Journal of the Experimental Analysis of Behavior, 11, 1-8.

Cumming, W. W., \& Berryman, R. (1965). Some data on matching behavior in the pigeon. Journal of the Experimental Analysis of Behavior, 4, 281-284.

Heise, G. A., \& Milar, K. S. (1984). Drugs and stimulus control. In L. Iversen, S. D. Iversen, \& S. H. Snyder (Eds.), Handbook of psychopharmacologyz: Vol. 18. Drugs, neurotransmitters, and behavior (pp. 129-190). New York: Plenum Press.

McCARThY, D., \& White, K. G. (in press). Behavioral models of delayed detection and their application to the study of memory. In M. L. Commons, J. Mazur, J. A. Nevin, \& H. C. Rachlin (Eds.), Quantitative analyses of behavior: Vol. 5. The effect of delay and of intervening events on reinforcement value. Cambridge: Ballinger.

McMillan, D. E. (1981). Effects of chemicals on delayed matching behavior in pigeons: I. Acute effects of drugs. Neurotoxicity, 2, 485-498.

Poling, A., Picker, M., \& Thomas, J. (1984). Effects of chlorprothixene, haloperidol, and trifluoperazine on the delayed matching-to-sample performance of pigeons. Pharamacology, Biochemistry, \& Behavior, 21, 721-726.

PonTeCORvo, M. J. (1983). Effects of proactive interference on rats' continuous nonmatching-to-sample performance. Animal Learning \& Behavior, 11, 356-366.

SCHECKEL, C. L.(1963). The effect of chlorpromazine (Thorazine) and chlordiazepoxide (Librium) on delayed matching responses in the Macca mulatta. Doctoral dissertation, Fordham University.

Scheckel, C., Boff, E., Dahlen, P., \& Smart, T. (1968). Behavioral effects in monkeys of racemates of two biologically active marijuana constituents. Science, 160, 1467-1469.

Thомpson, D. M. (1978). Stimulus control and drug effects. In D. E. Blackman \& J. Sanger (Eds.), Contemporary research in behavioral pharmacology (pp. 159-207). New York: Plenum Press.

WHITE, K. G. (1985). Characteristics of forgetting functions in delayed matching-to-sample. Journal of the Experimental Analysis of Behavior, 44, 15-34.

Wysocki, T., Fuqua, W., Davis, V. J., \& Breuning, S. E. (1981). Effects of thioridazine (Mellaril) on titrating delayed matching to sample performance of mentally retarded adults. American Journal of Mental Deficiency, 85, 539-547.

(Manuscript received for publication April 25, 1986.) 